\title{
Changes in fundus autofluorescence of choroidal melanomas following treatment
}

\begin{abstract}
Purpose We have previously shown that fundus autofluorescence (FAF) associated with pigmented choroidal lesions can be attributed to mainly lipofuscin (orange pigment) but also to hyperpigmentation, drusen, or fibrous metaplasia. The purpose of this study is to describe the effects of treatment on FAF in choroidal melanomas after plaque radiotherapy alone or in combination with transpupillary thermotherapy (TTT).

Methods Retrospective chart review of eight consecutive patients with choroidal melanoma treated with plaque radiotherapy alone or in combination with TTT who underwent FAF photography before and after treatment. The correlation between FAF patterns and foci of orange pigment, hyperpigmentation, drusen, or fibrous metaplasia was evaluated.
\end{abstract}

Results The median follow-up time was 4 (range 2-9) months. Foci of orange pigment and hyperpigmentation became larger and

Department of

Ophthalmology, Mayo

Clinic, Rochester, MN , USA

Correspondence: JS Pulido, Department of

Ophthalmology, 200 First St SW, Rochester, MN 55905,

USA

Tel: 507284 3721; Fax: 507 2844612.

Email: pulido.jose@

mayo.edu

Received: 8 March 2007 Accepted in revised form: 16 September 2007

Published online:

19 October 2007

Presented in part at the American Ophthalmological Society, White Sulphur Springs, WV, USA, 2007. more numerous after treatment. Fibrous metaplasia was also increased. A complete correlation between increased FAF and orange pigment was found in all eight tumours $\mathbf{( 1 0 0 \% )}$ before and after treatment. No correlation between hyperpigmentation and increased FAF was found before treatment but a partial correlation was found in all eyes after treatment. Before treatment, correlation between fibrous metaplasia was present in three eyes and increased FAF was partial in two eyes with no correlation in one case. After treatment, this correlation was partial in all presenting eyes (7).

Conclusions Following treatment, choroidal melanomas may show increased FAF, mainly due to an increase in the amount of lipofuscin (orange pigment) and hyperpigmentation. Eye (2009) 23, 428-434; doi:10.1038/sj.eye.6703004; published online 19 October 2007
L Amselem, JS Pulido, K Gunduz, SJ Bakri, M Diaz-Llopis, JW Dolan, K Morgan, S De Souza, T Link and J Rosvold

Keywords: autofluorescence; choroidal melanoma; plaque radiotherapy; transpupillary thermotherapy; lipofuscin

\section{Introduction}

Fundus autofluorescence (FAF) imaging uses fluorescent properties of some molecules, especially lipofuscin. ${ }^{1-3}$ Lipofuscin is a diverse group of molecular species, yellow to brown in colour and autofluorescent. ${ }^{2}$ Lipofuscin results from the oxidative breakdown of different molecules. The intensity of FAF parallels the amount and distribution of lipofuscin. The accumulation of autofluorescent pigment is seen in multiple disorders that affect the RPE and choroid. ${ }^{4,5}$ FAF derives from RPE and Bruch membrane, since the signal appears to be derived from the anterior to the choriocapillaris and posterior to the neuroretina. ${ }^{3}$

In dry age-related macular degeneration (ARMD) increased FAF was found to correlate with the areas of hyperpigmentation, soft drusen, hard drusen, or normal fundus appearance. ${ }^{6,7}$ Drusen may have an increased, normal, or decreased FAF signal, though soft drusen were more often associated with increased FAF than hard drusen. ${ }^{8,9}$ Several studies concluded that FAF imaging in dry ARMD does not necessarily correspond to the fundus changes observed, yet provides information over and above the normal fundus photography methods used. .,10 $^{-10}$

Active stages of acute central serous retinopathy (CSR) show an increase in FAF corresponding to increased metabolic activity of the retinal pigment epithelium (RPE), while chronic CSR shows decreased FAF probably due to the reduced metabolic activity of the RPE secondary to photoreceptor cell loss. ${ }^{11}$ In pseudoxanthoma elasticum and atrophic 
ARMD, atrophy of the RPE is associated with decreased FAF. $^{12,13}$

FAF has also been used to study the success of selective RPE destruction by laser treatment. Initial hypoautofluorescence is observed after treatment, but hyperautofluorescence appears after 1 week secondary to proliferation of the RPE. ${ }^{14}$

Lipofuscin can appear on the surface of several types of benign and malignant tumours as orange pigment. Although this finding is suggestive of malignancy, it is not diagnostic. ${ }^{15}$

We have previously shown that FAF associated with pigmented choroidal lesions can be attributed mainly to orange pigment but also to hyperpigmentation, drusen, or fibrous metaplasia. ${ }^{16}$

The aim of this study is to describe the effects of treatment on FAF in choroidal melanomas after plaque radiotherapy alone or in combination with transpupillary thermotherapy (TTT).

\section{Methods}

After obtaining the approval from the Institutional Review Board (IRB) of the Mayo Clinic, a retrospective chart review of patients with choroidal melanoma treated with plaque radiotherapy alone or in combination with TTT who underwent FAF photography before and after treatment was performed. All patients were examined at the Mayo Clinic between October 2005 and May 2006.

Patients underwent a complete ocular examination before and after treatment, including Snellen visual acuity, slit-lamp biomicroscopy, intraocular pressure, and fundoscopy. Optical coherence tomography (OCT), colour fundus photographs, autofluorescence photographs, fluorescein angiography, and A- and Bscan ultrasonography were also performed. Patients with significant media opacities were excluded from the study. Before and after treatment, colour fundus photographs were carefully evaluated for the presence and location of orange pigment, hyperpigmentation, fibrous metaplasia, drusen, and subretinal fluid. The presence of subretinal fluid was also determined by OCT.

FAF photography was performed with the Heidelberg confocal scanning laser ophthalmoscope (SLO) system (Heidelberg Retina Angiograph (HRA), Heidelberg Engineering, Dossenheim, Germany) that uses argon blue wavelength $(488 \mathrm{~nm})$ to excite autofluorescence. FAF images were carefully evaluated for the presence of different degrees of autofluorescence. FAF was then described as hyperfluorescent, isofluorescent, or hypofluorescent compared to the background autofluorescence of the rest of the retina.

The correlation between colour fundus findings and FAF images was graded from complete correlation (complete correspondence between increased FAF foci and fundus findings), partial correlation (at least one area of increased FAF related to the fundus findings) or no correlation (defined as the lack of hyperfluorescence).

\section{Results}

Eight patients, five men and three women, were included in this study. Patient demographics and tumour features before and after treatment are shown in Table 1. The median age was 57 years, ranging from 41 to 75 years. Of the eight tumours, six were pigmented, one was amelanotic, and one was partially pigmented. Two patients were treated with plaque radiotherapy alone and six patients were treated with plaque radiotherapy in combination with TTT. The median follow-up was 4 months (range 2-9 months).

Before treatment, the median largest tumour base (LTB) measured by ultrasonography was $10 \mathrm{~mm}$ (range 6-15 mm) and the median tumour thickness was $2.0 \mathrm{~mm}$ (range 1.2-4.1 mm). Following the treatment of choroidal melanomas, the median LTB decreased to $8.0 \mathrm{~mm}$ (range $5-15 \mathrm{~mm}$ ), and the median tumour thickness was $1.0 \mathrm{~mm}$ (range $0.6-2.9 \mathrm{~mm}$ ).

Before treatment the orange pigment was present in all eight tumours, hyperpigmentation in one tumour and fibrous metaplasia in three tumours while drusen were absent in all tumours. After treatment, orange pigment, hyperpigmentation, and fibrous metaplasia were present in all eight eyes. No drusen were seen. Foci of orange pigment and hyperpigmentation became larger and more numerous after treatment. Fibrous metaplasia was also increased. There was an increase in the total surface area of increased FAF following treatment.

Before treatment, all eyes had subretinal or intraretinal fluid on OCT. Following treatment, subretinal fluid was present in three eyes.

The degree of correlation scores between increased FAF patterns and orange pigment, hyperpigmentation, drusen, and fibrous metaplasia is shown in Table 2. A complete correlation between increased FAF and orange pigment was found in all eight tumours before and after treatment. No correlation between hyperpigmentation and increased FAF was found before treatment but a partial correlation was found in all eyes after treatment. Before treatment, correlation between fibrous metaplasia and increased FAF was partial in two eyes with no correlation in one case. After treatment this correlation was partial in all seven eyes. Areas of subretinal fluid presented a partial correlation with increased FAF before and following treatment.

Brief report of three cases:

Case 1 (Figure 1) was a 75-year-old-man with a documented growing pigmented choroidal melanoma 
Table 1 Patient demographics and tumour features in eight patients with high-risk choroidal melanocytic lesions treated with plaque radiotherapy alone or in combination with transpupillary thermal therapy (TTT) who underwent fundus autofluorescence (FAF) photography

\begin{tabular}{|c|c|c|c|c|c|c|c|c|c|c|c|c|c|}
\hline $\begin{array}{l}\text { Patient no } \\
\text { Treatment }\end{array}$ & $\begin{array}{c}\text { Age } \\
\text { (years) }\end{array}$ & $\begin{array}{l}\text { Follow-up } \\
\text { (months) }\end{array}$ & Sex & Location & $\begin{array}{l}\text { Tumour } \\
\text { base (mm) }\end{array}$ & $\begin{array}{l}\text { Tumour } \\
\text { height }(\mathrm{mm})\end{array}$ & Colour & $\begin{array}{l}\text { Orange } \\
\text { pigment }\end{array}$ & Hyperpig. & Drusen & Fib. meta. & SRF clin & SRF OCT \\
\hline $\begin{array}{l}\text { No } 1 \\
\text { TTT }+ \text { BT }\end{array}$ & 75 & 4 & M & Macular & $\begin{array}{l}10 \times 8 \text { pre } \\
10 \times 8 \text { post }\end{array}$ & $\begin{array}{l}2.4 \text { pre } \\
1.5 \text { post }\end{array}$ & Pig & Pre + & - & - & - & - & SR \\
\hline $\begin{array}{l}\text { No } 2 \\
\text { TTT + BT }\end{array}$ & 57 & 2 & M & $\begin{array}{l}\text { Supero- } \\
\text { temporal }\end{array}$ & $\begin{array}{l}5 \times 6 \text { pre } \\
5 \times 6 \text { post }\end{array}$ & $\begin{array}{l}\text { 1.81 pre } \\
0.91 \text { post }\end{array}$ & Pig & $\begin{array}{l}\text { Post }+ \\
\text { Pre }+\end{array}$ & $\begin{array}{l}+ \\
-\end{array}$ & $\begin{array}{l}- \\
-\end{array}$ & $\begin{array}{l}+ \\
-\end{array}$ & $\begin{array}{l}- \\
+\end{array}$ & $\begin{array}{l}- \\
\text { SR }\end{array}$ \\
\hline & & & & & & & & Post + & + & - & + & - & SR \\
\hline $\begin{array}{l}\text { No } 3 \\
\text { TTT + BT }\end{array}$ & 58 & 3.5 & M & $\begin{array}{l}\text { Infero- } \\
\text { temporal }\end{array}$ & $\begin{array}{l}5 \times 6 \text { pre } \\
5 \times 6 \text { post }\end{array}$ & $\begin{array}{l}1.8 \text { pre } \\
1.0 \text { post }\end{array}$ & Pig. & $\begin{array}{l}\text { Pre }+ \\
\text { Post }+\end{array}$ & $\begin{array}{l}+ \\
+\end{array}$ & $\begin{array}{l}- \\
-\end{array}$ & $\begin{array}{l}+ \\
+\end{array}$ & $\begin{array}{l}- \\
-\end{array}$ & $\begin{array}{l}\text { SR IR } \\
-\end{array}$ \\
\hline $\begin{array}{l}\text { No } 4 \\
\text { BT }\end{array}$ & 41 & 7 & F & Temporal & $\begin{array}{l}10 \times 9 \text { pre } \\
7.5 \times 6 \text { post }\end{array}$ & $\begin{array}{l}\text { 4.1pre } \\
2.9 \text { post }\end{array}$ & Par. Pig. & Pre + & - & - & + & + & SR \\
\hline $\begin{array}{l}\text { No } 5 \\
\text { BT }\end{array}$ & 55 & 4 & $\mathrm{~m}$ & Infero-nasal & $\begin{array}{l}15 \times 12 \text { pre } \\
15 \times 12 \text { post }\end{array}$ & $\begin{array}{l}1.2 \text { pre } \\
1.2 \text { pre }\end{array}$ & Amel. & $\begin{array}{l}\text { Post }+ \\
\text { Pre }+\end{array}$ & $\begin{array}{l}+ \\
-\end{array}$ & $\begin{array}{l}- \\
-\end{array}$ & $\begin{array}{l}+ \\
+\end{array}$ & $\begin{array}{l}+ \\
+\end{array}$ & $\begin{array}{c}+ \\
\text { SR }\end{array}$ \\
\hline $\begin{array}{l}\text { No } 6 \\
\text { TTT + BT }\end{array}$ & 64 & 9 & $\mathrm{~m}$ & $\begin{array}{l}\text { Supero- } \\
\text { temporal }\end{array}$ & $\begin{array}{l}10 \times 8 \text { pre } \\
10 \times 8 \text { post }\end{array}$ & $\begin{array}{l}2.1 \text { pre } \\
0.6 \text { post }\end{array}$ & Pig. & $\begin{array}{l}\text { Post }+ \\
\text { Pre }+\end{array}$ & $\begin{array}{l}+ \\
-\end{array}$ & $\begin{array}{l}- \\
-\end{array}$ & $\begin{array}{l}+ \\
-\end{array}$ & $\begin{array}{l}+ \\
+\end{array}$ & $\begin{array}{l}\text { SR } \\
\text { SR }\end{array}$ \\
\hline $\begin{array}{l}\text { No } 7 \\
\text { TTT + BT }\end{array}$ & 54 & 5 & F & Infero-nasal & $\begin{array}{l}8 \times 8 \text { pre } \\
8 \times 8 \text { post }\end{array}$ & $\begin{array}{l}2.3 \text { pre } \\
1.0 \text { post }\end{array}$ & Pig. & $\begin{array}{l}\text { Post }+ \\
\text { Pre }+\end{array}$ & $\begin{array}{l}+ \\
-\end{array}$ & $\begin{array}{l}- \\
-\end{array}$ & $\begin{array}{l}+ \\
-\end{array}$ & $\begin{array}{l}- \\
+\end{array}$ & $\begin{array}{l}- \\
\text { SR }\end{array}$ \\
\hline $\begin{array}{l}\text { No } 8 \\
\text { TTT + B }\end{array}$ & 73 & 6 & F & Infero-nasal & $\begin{array}{l}13 \times 10 \text { pre } \\
13 \times 10 \text { post }\end{array}$ & $\begin{array}{l}2.0 \text { pre } \\
1.2 \text { post }\end{array}$ & Pig. & $\begin{array}{l}\text { Post }+ \\
\text { Pre }+\end{array}$ & $\begin{array}{l}+ \\
-\end{array}$ & $\begin{array}{l}- \\
-\end{array}$ & $\begin{array}{l}+ \\
-\end{array}$ & $\begin{array}{l}- \\
+\end{array}$ & $\begin{array}{l}- \\
\mathrm{SR}\end{array}$ \\
\hline & & & & & & & & Post + & + & - & + & - & - \\
\hline
\end{tabular}

-: -, absent; +: +, present; Amel, amelanotic; BT, braquitherapy; F, female; Fibr. Meta, fibrous metaplasia; Hyperpig, hyperpigmentation; M, male; Par. Pig., partially pigmented; Pig., pigmented; Post, following treatment; Pre, pretreatment; TTT, transpupillary thermotherapy. 
Table 2 Correlation with FAF and fundus findings

\begin{tabular}{|c|c|c|c|c|c|}
\hline Patient no. & Treatment (follow-up) & Orange pigment & Hyperpigmentation & Drusen & $\begin{array}{l}\text { Fibrous } \\
\text { metaplasia }\end{array}$ \\
\hline \multirow[t]{2}{*}{1} & \multirow[t]{2}{*}{ TTT + BT (4 months) } & Pre Complete & - & - & - \\
\hline & & Post Complete & Partial & - & Partial \\
\hline \multirow[t]{2}{*}{2} & \multirow{2}{*}{ TTT + BT (2 months) } & Pre Complete & - & - & - \\
\hline & & Post Complete & Partial & - & Partial \\
\hline \multirow[t]{2}{*}{3} & \multirow[t]{2}{*}{ TTT + BT (3.5 months) } & Pre Complete & None & - & None \\
\hline & & Post Complete & Partial & - & Partial \\
\hline \multirow[t]{2}{*}{4} & \multirow[t]{2}{*}{ BT (7 months) } & Pre Complete & - & - & Partial \\
\hline & & Post Complete & Partial & - & Partial \\
\hline \multirow[t]{2}{*}{5} & \multirow[t]{2}{*}{ BT (4 months) } & Pre Complete & - & - & Partial \\
\hline & & Post Complete & Partial & - & Partial \\
\hline \multirow[t]{2}{*}{6} & \multirow[t]{2}{*}{ TTT + BT (9 months) } & Pre Complete & - & - & - \\
\hline & & Post Complete & Partial & - & Partial \\
\hline \multirow[t]{2}{*}{7} & \multirow[t]{2}{*}{ TTT + BT (5 months) } & Pre Complete & - & - & - \\
\hline & & Post Complete & Partial & - & Partial \\
\hline \multirow[t]{2}{*}{8} & \multirow[t]{2}{*}{ TTT + BT (6 months) } & Pre Complete & - & - & - \\
\hline & & Post Complete & Partial & - & Partial \\
\hline
\end{tabular}

-, not applicable.

BT, braquitherapy; FAF, fundus autofluorescence; Post, post-treatment; Pre, pre-treatment; TTT, transpupillary thermotherapy.

a

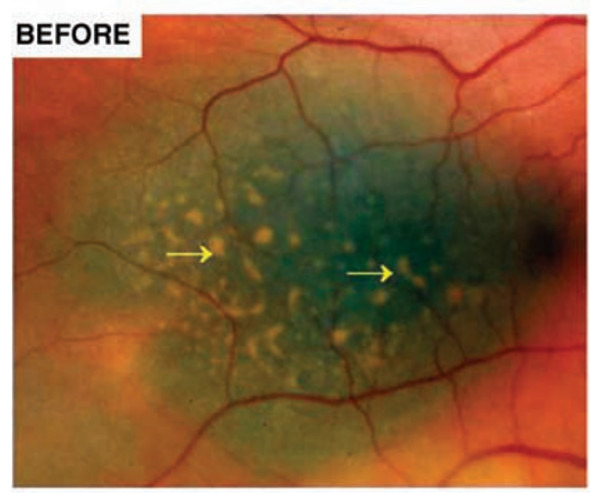

b

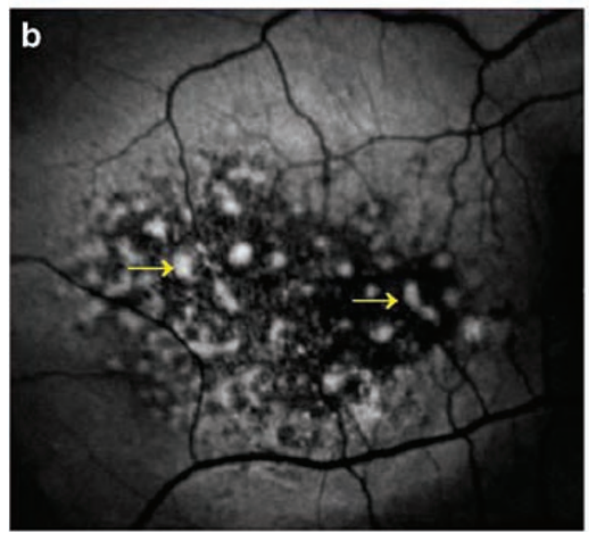

c
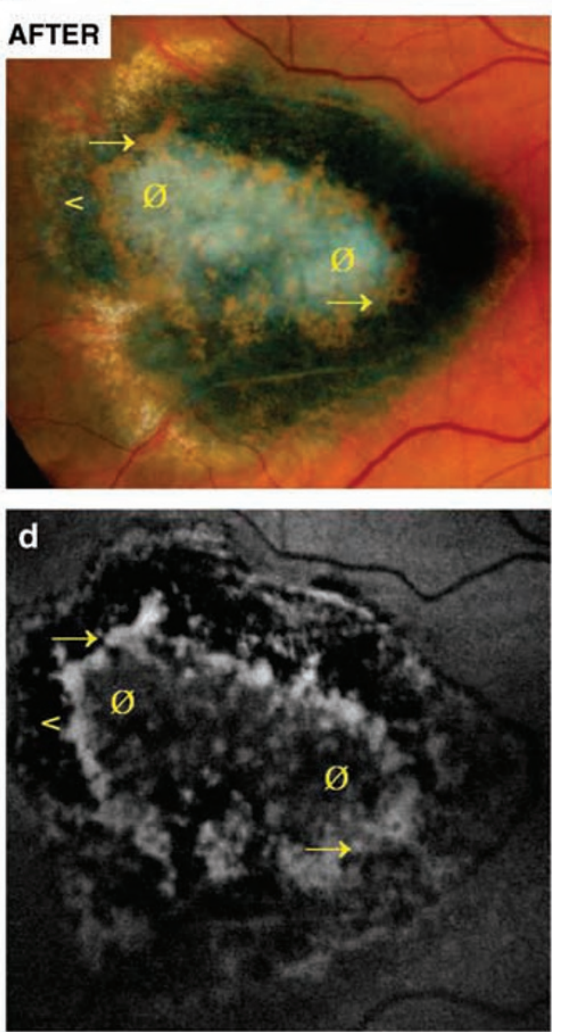

Figure 1 Patient 1. Right eye: Colour fundus photograph (a and c) and fundus autofluorescence (FAF) photograph of a choroidal melanoma ( $b$ and $d)$ before and after treatment with plaque radiotherapy and transpupillary thermotherapy (TTT). Before treatment (a and b) the melanoma had orange pigment (arrow) that showed complete correlation with increased FAF. Following treatment (c and d) (4 months), fundus photography shows an increase in orange pigment (with complete correlation with increased FAF), hyperpigmentation $(<)$ (with partial correlation with increased FAF), and fibrous metaplasia (Ø) (with partial correlation with increased FAF). 
located in the macular zone with orange pigment and subretinal fluid who underwent plaque radiotherapy and TTT. Before treatment there was a complete correlation between increased FAF and orange pigment. Areas of subretinal fluid showed slight hyper-FAF. Following treatment (4 months), orange pigment foci became larger and more numerous (with a complete correlation with increased FAF), hyperpigmentation increased (with partial correlation with increased FAF), and fibrous metaplasia appeared (with partial correlation with increased FAF). Areas of subretinal fluid before treatment showed mild hyperpigmentation.

Case 2 (Figure 2) was a 57-year-old man with a documented growing pigmented choroidal melanoma, superotemporal to the fovea, with orange pigment and subretinal fluid who underwent plaque radiotherapy and TTT. Before treatment orange pigment showed a complete correlation with increased FAF. Areas of subretinal fluid also showed hyper-FAF. Two months after treatment, we observed an increase in orange pigment (with complete correlation with increased FAF) and the presence of hyperpigmentation (with partial correlation with increased FAF). Mild subretinal fluid was still present, showing partial correlation with increased FAF.

Case 3 (Figure 3) was a 58-year-old man with a documented growing pigmented choroidal lesion, starting at the optic nerve margin and extending inferotemporal to the fovea with orange pigment, fibrous metaplasia, hyperpigmentation, and subretinal fluid, who underwent plaque radiotherapy and TTT. Before treatment, there was a complete correlation with increased FAF and orange pigment, and fibrous metaplasia had a partial correlation with increased FAF. Hyperpigmentation appeared as hypofluorescent. Areas of subretinal fluid were also hyper-FAF, with partial correlation. Following treatment ( 3.5 months), there was an increase in orange pigment (with a complete a
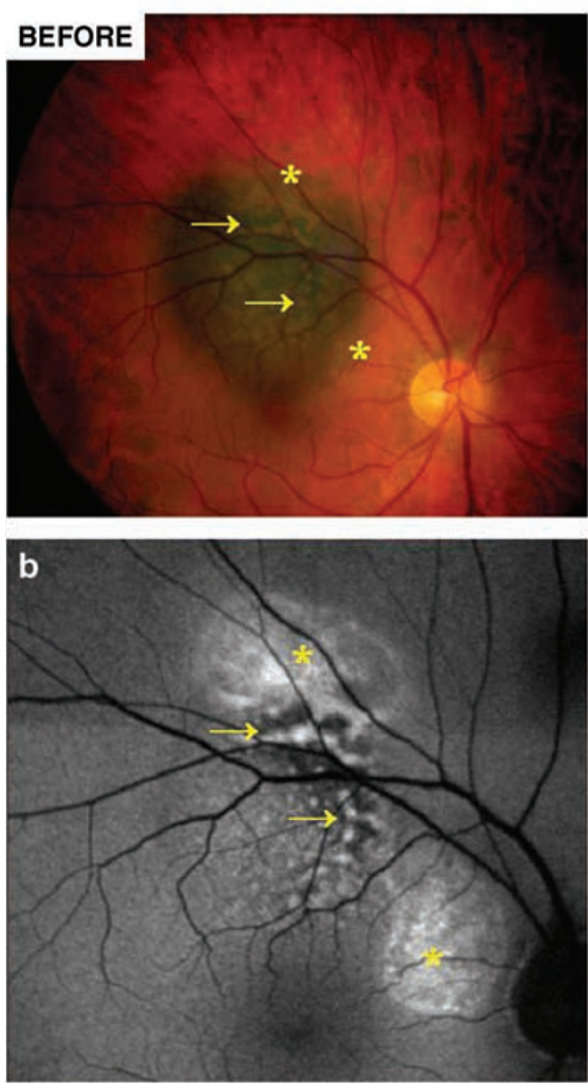

\section{c}
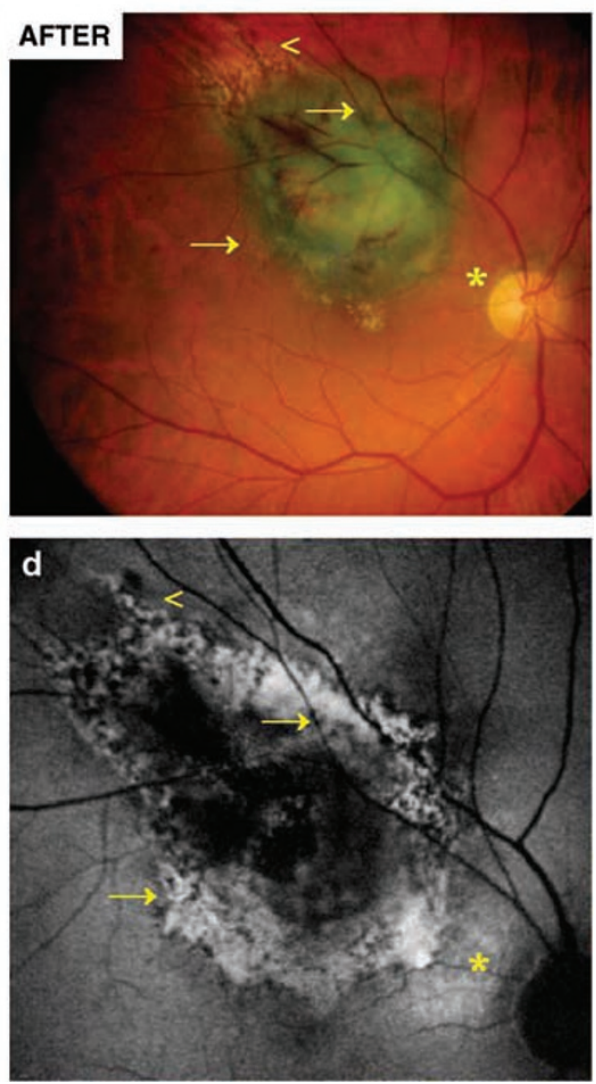

Figure 2 Patient 2. Right eye: colour fundus photograph (a and c) and fundus autofluorescence (FAF) photograph of a choroidal melanoma ( $b$ and $d$ ) before and after treatment with transpupillary thermotherapy (TTT) followed by plaque radiotherapy. Before treatment $(a, b)$ the lesion showed orange pigment (arrow) that showed complete correlation with increased FAF. Areas of subretinal fluid $\left(^{*}\right)$ also show hyper-FAF. Two months after treatment (c and d), colour fundus photograph shows an increase in orange pigment (with complete correlation with increased FAF) and the presence of hyperpigmentation $(<)$ (with partial correlation with increased FAF). 
a
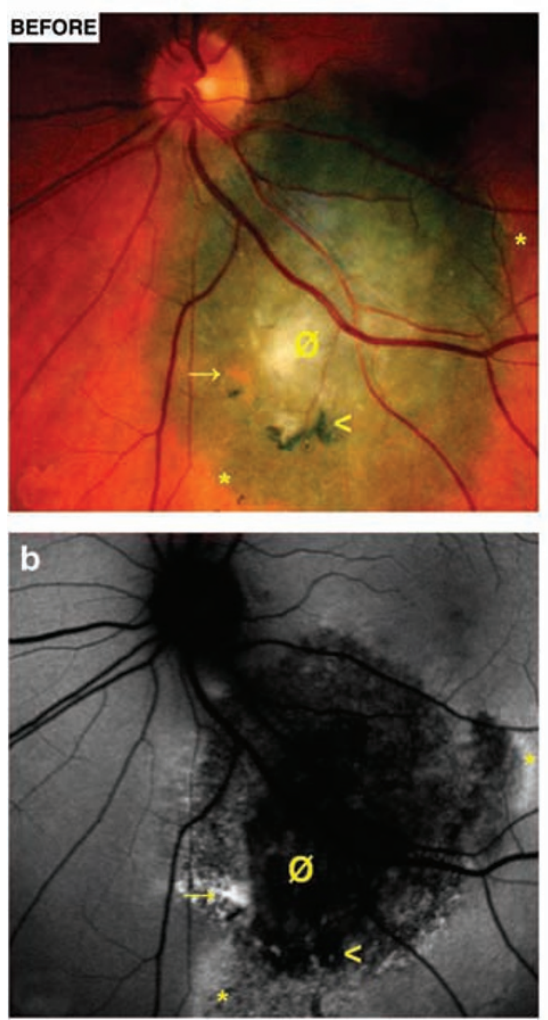

c
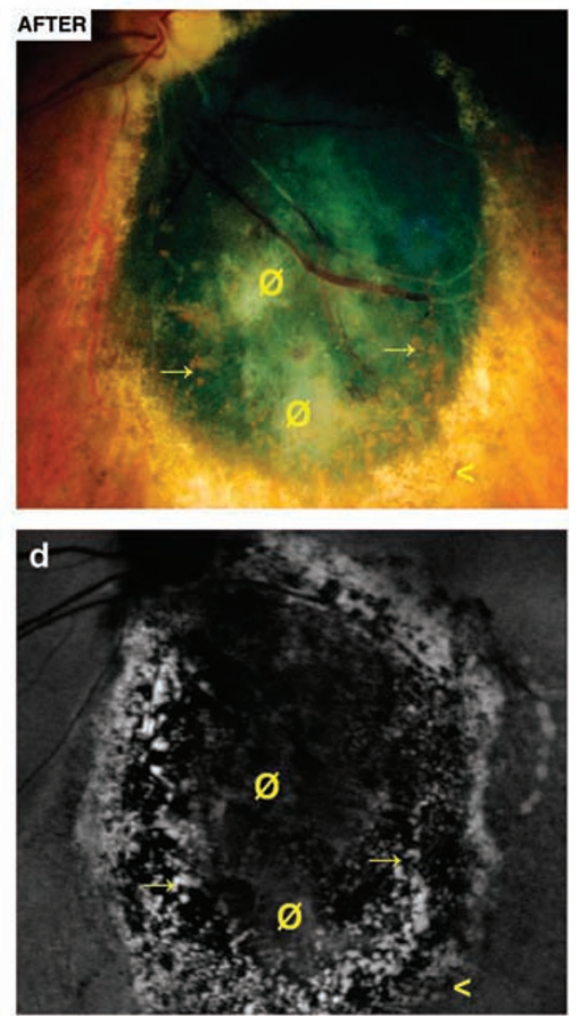

Figure 3 Patient 3. Left eye: colour fundus photograph (a and c) and fundus autofluorescence (FAF) photograph (b and d) before (a and b) and after (c and d) treatment. This patient underwent transpupillary thermotherapy (TTT) followed by plaque radiotherapy. Before treatment the patient has orange pigment (arrow) that shows complete correlation with increased FAF, fibrous metaplasia (Ø) with partial increased FAF correlation, and hyperpigmentation $(<)$ with no FAF. Areas of subretinal fluid $\left(^{*}\right)$ also show hyper-FAF. Following treatment (3.5 months), colour fundus photograph shows an increase in orange pigment (with complete correlation with increased FAF), more hyperpigmentation (with partial correlation with increased FAF), and more fibrous metaplasia (with partial correlation with increased FAF)

correlation with increased FAF), hyperpigmentation (with a partial correlation with increased FAF), and more fibrous metaplasia (with a partial correlation with increased FAF). Areas with subretinal fluid before treatment showed mild hyperpigmentation (with a partial correlation with increased FAF).

\section{Discussion}

In our study, all the tumours showed many foci of increased autofluorescence signal before and after treatment. Orange pigment showed a complete correlation with increased FAF, hyperpigmentation and fibrous metaplasia showed a partial correlation with increased FAF as these areas had at least one focus of increased FAF in all the eyes following treatment. Subretinal fluid was also associated with increased FAF The strongest FAF signal was in the presence of orange pigment.
Following treatment, choroidal melanomas showed an increase in FAF mostly due to an increase in the amount of orange pigment (lipofuscin) and hyperpigmentation.

Foci of lipofuscin and hyperpigmentation became larger and more numerous after treatment. The increase of lipofuscin, observed in melanomas after treatment, might be secondary to the oxidative stress suffered by the RPE cells and the necrosing tumour.

The presence of lipofuscin on the surface of choroidal melanocytic lesions is sometimes hard to determine as lipofuscin has variable colours depending on the nature and colour of the underlying lesion. It may be very difficult to determine its presence in many lesions.

The excellent correlation between increased FAF and orange pigment makes FAF a useful adjunct to help in confirming or detecting the presence of lipofuscin. Orange pigment (lipofuscin) is one of the risk factors for malignancy of a choroidal melanocytic lesion. Other risk factors are the presence of subretinal fluid, tumour thickness greater than $2 \mathrm{~mm}$, the proximity of the lesion 
to the optic nerve, and the presence of visual symptoms. ${ }^{17}$ Since the risk of tumour growth depends on the number of risk factors present, ${ }^{17}$ it is important to accurately determine the presence or absence of each of these.

The partial correlation between fibrous metaplasia and a mildly increased FAF pattern observed in melanomas following treatment may be due to a subtle accumulation of lipofuscin in these areas and alternatively it may be related to pseudofluorescence from the white tissue.

The partial correlation between FAF and hyperpigmentation may be secondary to the increased metabolic activity of the RPE during the proliferation that follows the destruction, also seen after laser treatment. ${ }^{14}$

The presence of hyperfluorescence in areas with subretinal fluid corroborates the same finding in active stages of acute central serous retinopathy (CSR) due to increased metabolic activity of the RPE. ${ }^{11}$

Furthermore, this study shows that choroidal melanomas develop increased FAF shortly after treatment, mostly due to an increase in the amount of orange pigment (lipofuscin) and hyperpigmentation.

Limitations of our study are dependent on the technique and design. One of the major limitations of the use of FAF to determine the presence of orange pigment in choroidal elevated lesions with the confocal scanning laser ophthalmoscope used in this study is that it has a depth of field of only about $300 \mu \mathrm{m}$, so fluorescence from deeper layers can not be detected. Increased retinal thickness, intraretinal oedema, or presence of subretinal fluid may then affect the FAF signal. This is an important consideration for thick choroidal tumours.

Another limitation of the FAF capture method used in our study is that an optimal autofluorescence image can only be obtained when the studied surface is in focus, so FAF areas, which are not in focus can be underestimated.

These factors along with the fact that FAF imaging is dependent on ocular media transparency and on the variable features of the different capture devices limits the reproducibility and consistency of many FAF studies. $^{18}$

This was a small retrospective study but adds to the evidence from the previous two studies from our group that orange pigment is strongly autofluorescent. ${ }^{16}$ In addition, further studies are indicated to determine if there may be a relationship between the increasing FAF patterns following treatment and the efficiency of plaque radiotherapy, TTT, and other treatment options.

\section{Acknowledgements}

This study was supported in part by an unrestricted grant from Research to Prevent Blindness Inc. NY, USA.

\section{References}

1 Rovati L, Docchio F. Autofluorescence methods in ophthalmology. J Biomed Opt 2004; 9: 9-21.

2 Eldred GE, Katz ML. Fluorophores of the retinal pigment epithelium: separation and spectral characterization. Exp Eye Res 1988; 47: 71-86.

3 Delori FC, Dorey CK, Staurenghi G, Arend O, Goger DG, Weiter JJ. In vivo fluorescence of the ocular fundus exhibits retinal pigment epithelium lipofuscin characteristics. Invest Ophthalmol Vis Sci 1995; 36: 718-729.

4 Von Rückmann A, Fitzke FW, Bird AC. In vivo fundus autofluorescence in macular dystrophies. Arch Ophthalmol 1997; 115: 609-615.

5 Lois N, Halfyard AS, Bird AC, Holder GE, Fitzke FW. Fundus autofluorescence in Stargardt macular dystrophyfundus flavimaculatus. Am J Ophthalmol 2004; 138: 55-63.

6 Von Rückmann A, Fitzke FW, Bird AC. Fundus autofluorescence in age-related macular disease imaged with a scanning laser ophthalmoscope. Invest Ophthalmol Vis Sci 1997; 38: 478-486.

7 Solbach U, Keilhauer C, Knabben H, Wolf S. Imaging of retinal autofluorescence in patients with age-related macular degeneration. Retina 1997; 17: 385-389.

8 Lois N, Owens SL, Coco R, Hopkins J, Fitzke FW, Bird AC. Fundus autofluorescence in patients with age-related macular degeneration and high risk of visual loss. Am J Ophthalmol 2002; 133: 341-349.

9 Einbock W, Moessner A, Schnurrbusch UE, Holz FG, Wolf S, FAM Study Group. Changes in fundus autofluorescence in patients with age-related maculopathy. Correlation to visual function: a prospective study. Graefes Arch Clin Exp Ophthalmol 2005; 243: 300-305.

10 Bindewald A, Bird AC, Dandekar SS, Dolar-Szczasny J, Dreyhaupt J, Fitzke FW et al. Classification of fundus autofluorescence patterns in early age-related macular disease. Invest Ophthalmol Vis Sci 2005; 46: 3309-3314.

11 von Rückman A, Fitzke FW, Fan J, Halfyard A, Bird AC. Abnormalities of fundus autofluorescence in central serous retinopathy. Am J Ophthalmol 2002; 133: 780-786.

12 Sawa M, Ober MD, Freund KB, Spaide RF. Fundus autofluorescence in patients with pseudoxanthoma elasticum. Ophthalmology 2006; 113: 814-820.

13 Sunness JS, Ziegler MD, Applegate CA. Issues in quantifying atrophic macular disease using retinal autofluorescence. Retina 2006; 26: 666-672.

14 Framme C, Brinkmann R, Birngruber R, Roider J. Autofluorescence imaging after selective RPE laser treatment in macular diseases and clinical outcome: a pilot study. Br J Ophthalmol 2002; 86: 1099-1106.

15 Shields JA, Rodrigues MM, Sarin LK, Tasman WS, Annesley Jr WH. Lipofuscin pigment over benign and malignant choroidal tumors. Trans Am Ophthalmol Soc 1976; 81(5): 871-881.

16 Gunduz K, Pulido JS, Bakri S, Petit-Fond E, Link T. Fundus autofluorescence of choroidal melanocytic lesions. Retina 2007; 27(6): 681-687.

17 Shields CL, Cater J, Shields JA, Singh AD, Santos MC, Carvalho C. Combination of clinical factors predictive of growth of small choroidal melanocytic tumors. Arch Ophthalmol 2000; 118: 360-364.

18 Hopkins J, Walsh A, Chakravarthy U. Fundus autofluorescence in age-related macular degeneration: an epiphenomenon? Invest Ophthalmol Vis Sci 2006; 47(6): 2269-2271. 